\title{
G.S. Beloglazov
}

State University of Russia, Department of Chemistry, 236040 Kaliningrad

drgeorge59@mail.ru

\section{QUANTUM CHEMICAL STUDY OF ORGANIC INHIBITORS OF CORROSION AND HYDROGEN ABSORPTION}

\begin{abstract}
Results of quantum chemical calculations of the molecules of organic inhibitors (Oin) of corrosion and hydrogen absorption by metals (particularly, p- $\mathrm{R}-\mathrm{C}_{6} \mathrm{H}_{4}-\mathrm{SO}_{2}-\mathrm{NH}_{2}$ where $\mathrm{R}=\mathrm{F}, \mathrm{Cl}, \mathrm{Br}, \mathrm{CH}_{3}$ ) both in free state and adsorbed on cluster modeling aluminium surface containing 20 atoms of $\mathrm{Al}$ are compared to experimental data on efficiencies of protective action (EPA) against corrosion by this metal. Energies of boundary orbitals (HOMO, LUMO) and dipole moments of isolated molecules of Oin as well as changes of atomic charges on Oin atoms when Oin molecule adsorbed have been computed using semi-empiric MNDO quantum chemistry method. It was found that correlation coefficients between EPA and changes of electric charge on $N$ atom $[\Delta Q(N)]$ and $O$ atom $[\Delta \mathrm{Q}(\mathrm{O})]$ due to adsorption of Oin on the metal surface are the most significant. At adsorption and eventually the protection action of Oin, the specific role of polar groups (such as hydroxile) and specific role of heteroatoms (such as $\mathrm{N}, \mathrm{S}$ etc) in the framework of the concepts of molecular orbitals and donor-acceptor interaction between adsorbent and adsorbate.
\end{abstract}

Keywords: Quantum Chemistry, Corrosion Inhibitor, Protective Action, Boundary Orbitals, HOMO, LUMO, Mulliken Charges, MNDO, Heteroatom, Adsorption, Hydrogen Absorption, Pair Correlation, Quantum Chemical Descriptors.

\section{APPROACH TO THE STUDY OF MECHANISM OF INHIBITIVE ACTION}

The state-of-the-art achievements made so far thanks to tremendous developments in computer technologies presently make it possible to replace some of the expensive technical experiments (including organic synthesis of inhibitors of corrosion and hydrogen absorption by metals) for various application media and conditions with computational simulations, provided capacity of modern computers enable to solve the complicated problems such as the tasks of quantum chemistry where the operations on high order matrices are required in order to perform calculations of the properties of real multi-atomic systems using well defined methods. Just as an example, the opportunity of modelling adsorption of molecular systems containing up to say 80 atoms $(20 \ldots 40$ of which are representing metal adsorbent within a cluster «adsorbed Oin + adsorbent») even using the most well defined (and thus the most complicated) quantum chemical methods (i.e. ab initio methods) is now feasible [1-10], and no more an utopia. The task of such «digital experiment» is to serve the aim of purposeful organic synthesis of efficient inhibitors of corrosion and hydrogen absorption of metals on the 
basis of known qualitative and quantitative structure-to-property relationships. On the first stage of such modelling, it is worth to find out: (1) which quantum chemical descriptors (QCD) being obtained from the computations prove to be in significant (and best if one to one) relationship with experimental data on efficiency against corrosion and hydrogen absorption, (2) the right size of polyatomic cluster which, on one hand, already correctly maps the qualitative and quantitative dependencies characterizing the important processes involving metal protection (including adsorption of Oin on the surface of metal being protected) and their results (taking into account the status of the media and other conditions of corrosion and/or hydrogen absorption), on another hand, a researcher is not yet exposed to massive problems of too long calculations.

\section{QUANTUM CHEMICAL STUDY OF ADSORPTION OF ORGANIC INHIBITORS OF HYDROGENATION ON AL AND CD SURFACE}

Below are given some examples of quantum chemical modelling applied for different metal adsorbents (such as $\mathrm{Al}$ and $\mathrm{Cd}$ ) at various conditions of surface (oxide, hydroxide, pure metal - the latter practically justified for most cases of natural or industrial electrolytes and other solutions particularly at electrochemical processes).

Table 1. Correlation coefficients between experimentally measured. Efficiencies of Inhibitive Action against Corrosion (EIAC) and theoretically computed QCD when modelling adsorption of Oin on $\mathrm{Al}_{2} \mathrm{O}_{3}$ and $\mathrm{Al}(\mathrm{OH})_{3}$

\begin{tabular}{|c|c|c|c|}
\hline \multirow{2}{*}{$\begin{array}{c}\text { Pair correlation } \\
\text { coefficients between } \\
\begin{array}{c}\text { EIAC and QCD at } \\
\text { different } \\
\text { concentrations of } \\
\text { Oin, mMol/L }\end{array}\end{array}$} & $\begin{array}{c}|c| \\
\text { Dipole moment } \\
\mathrm{p}_{\mathrm{o}} \\
\text { of Oin isolated } \\
\text { molecule }\end{array}$ & $\begin{array}{c}\text { Quantum Chemical Descriptors (QCD) } \\
\text { Most probable angle } \alpha^{\circ} \\
\text { between the changed } \\
\text { dipole moment of Oin } \\
\text { molecule and surface } \\
\text { normal to } \mathrm{Al}_{20}\end{array}$ & $\begin{array}{c}\text { Relative change of } \\
\text { module of dipolar } \\
\text { moment } \Delta \mathrm{p}_{\text {ad }} \text { of Oin } \\
\text { molecule when } \\
\text { adsorbed on cluster } \\
\text { modelling } \mathrm{Al}_{20}\end{array}$ \\
\hline 1 & $-55 \%$ & $-46 \%$ & $0 \%$ \\
\hline 5 & $-67 \%$ & $-58 \%$ & $21 \%$ \\
\hline 10 & $-68 \%$ & $-67 \%$ & $30 \%$ \\
\hline 15 & $-74 \%$ & $-73 \%$ & $37 \%$ \\
\hline
\end{tabular}

In table 1, some quantum chemical characteristics QCD computed using the restricted Hartree-Fock $a b$ initio (STO-3G) method implemented in the software [11] are compared to the experimental data obtained for the same Oin (six various substituted phenols).

When computing the most probable angle between the vector of dipole moment of adsorbed Oin molecule and the normal to flat metal surface (see Table 1) the fact that dipole moment of Oin molecule is changed (modified) on adsorption of that molecule, is taken into account. 
Table 2. Values of EIAC and QCD for Oin «D1...D5»

\begin{tabular}{|c|c|c|c|c|c|c|}
\hline \multirow[t]{2}{*}{ Oin Title } & \multicolumn{3}{|c|}{$\begin{array}{l}\text { EIAC }(\%) \text { of the studied inhibitors of } \\
\text { steel corrosion by cadmium plating at } \\
\text { concentrations of Oin, mMol/L } \\
\text { (numerator }-D_{k}=1 \mathrm{~A} / \mathrm{dm}^{2}, \\
\left.\text { denominator }-D_{k}=3 \mathrm{~A} / \mathrm{dm}^{2}\right) \text { : }\end{array}$} & \multirow[t]{2}{*}{$\begin{array}{l}\text { Computed } \\
\text { dipole } \\
\text { moment of } \\
\text { Oin } \\
\text { molecule, D }\end{array}$} & \multirow{2}{*}{$\begin{array}{l}\text { Electric charge } \\
\text { summed over } \\
\text { all atoms of } \\
\text { adsorbed OA } \\
\text { molecule when } \\
\text { adsorbed on } \\
\mathrm{Cd}_{22} \\
\text { modelling } \\
\text { fragment } \\
\left(\Delta \mathrm{Q}_{\text {ад, }}, \mathrm{e} \mid\right)\end{array}$} & \multirow{2}{*}{$\begin{array}{l}\text { Absolute } \\
\text { change in the } \\
\text { module of } \\
\text { dipole moment } \\
\text { of OA } \\
\text { molecule when } \\
\text { adsorbed on } \\
\mathrm{Cd}_{22} \\
\text { modelling }_{\text {fragment }} \\
\left(\Delta \mathrm{p}_{\mathrm{ad}}, \mathrm{D}\right)\end{array}$} \\
\hline & 1 & 2 & 5 & & & \\
\hline D1 & $78 / 44$ & $81 / 54$ & $84 / 56$ & 1.65 & -2.356 & 5.532 \\
\hline D2 & $78 / 46$ & $84 / 58$ & $81 / 58$ & 14.90 & -2.192 & 7.456 \\
\hline D3 & $84 / 51$ & $86 / 63$ & $86 / 63$ & 10.56 & -2.402 & 1.816 \\
\hline D4 & 84 / 56 & 89 / 66 & $89 / 66$ & 8.85 & -1.955 & 2.580 \\
\hline D5 & $84 / 61$ & $89 / 71$ & $89 / 68$ & 19.19 & -2.173 & -0.889 \\
\hline
\end{tabular}

Some results for five different substituted diantipirylmethanes («D1...D5» as Oin in the role of inhibitors of hydrogen absorption by steel by cadmium electroplating) obtained using the same quantum chemical method i.e. restricted Hartree-Fock ab initio (STO-3G) (program [11]) are listed in table 2.

Table 3. Pair correlation coefficients between EIAC and QCD

\begin{tabular}{|c|c|c|c|c|}
\hline \multirow[b]{2}{*}{$\begin{array}{l}\text { Oin } \\
\text { concentration, } \\
\mathrm{mMol} / \mathrm{L}\end{array}$} & \multirow[b]{2}{*}{$\begin{array}{l}\text { Current density } D_{k} \text {, } \\
\qquad / \mathrm{dm}^{2}\end{array}$} & \multicolumn{3}{|c|}{ Quantum Chemical Characteristics (QCD) } \\
\hline & & $\begin{array}{l}\text { Dipole moments of } \\
\text { isolated Oin } \\
\text { molecules }\left(\mathrm{p}_{\mathrm{o}}\right)\end{array}$ & $\begin{array}{c}\text { Electric charge } \\
\text { summed over all } \\
\text { atoms of adsorbed } \\
\mathrm{OA} \text { molecule } \\
\text { when adsorbed on } \\
\mathrm{Cd}_{22} \text { modelling } \\
\text { fragment }\left(\Delta \mathrm{Q}_{\mathrm{ad}}\right)\end{array}$ & $\begin{array}{l}\text { Absolute change in } \\
\text { the module of } \\
\text { dipole moment of } \\
\text { OA molecule when } \\
\text { adsorbed on } \mathrm{Cd}_{22} \\
\text { modelling fragment } \\
\qquad\left(\Delta \mathrm{p}_{\mathrm{ad}}\right)\end{array}$ \\
\hline 1 & 3 & $63 \%$ & $52 \%$ & $-89 \%$ \\
\hline 1 & 2 & $81 \%$ & $64 \%$ & $-70 \%$ \\
\hline 2 & 2 & $72 \%$ & $65 \%$ & $-76 \%$ \\
\hline 5 & 2 & $69 \%$ & $48 \%$ & $-89 \%$ \\
\hline 5 & 3 & $60 \%$ & $51 \%$ & $-89 \%$ \\
\hline
\end{tabular}

Concentration dependences of the found correlation coefficients between experimentally measured efficiencies of inhibitive action and theoretically computed values of the most probable angle between the vector of dipole moment (please note also the remark to Table 1) of Oin molecule as a result of adsorption on the surface of $\mathrm{Al}$ alloy and the surface normal of metal being modeled, are simbate in all three studied cases of condition of such surface, namely $\mathrm{Al}_{20},\left\{4 \mathrm{Al}_{2} \mathrm{O}_{3}\right\}$ and $\left\{4 \mathrm{Al}(\mathrm{OH})_{3}\right\}$. Comparison of the pair correlation coefficients given in Tables 2 and 3 gives the evidence that mechanism of protection of metal against hydrogen absorption and against corrosion are different in case of $\mathrm{Cd}$ plating of steel and $\mathrm{Al}$ as chief component of some industrial duralumin alloys.

Furthermore, a series of nine Oin (hydrazides and hydrazones, four of which are the derivatives of glycolic acid) was studied in three qualities: as inhibitors of hydrogen 
absorption of steel (a), corrosion inhibitors (b), and biocides against mushroom growth on metal surface (c). Results are listed below in Tables $4 \div 9$ :

Table 4. Correlation coefficients between efficiencies of the studied Oin (derivatives of glycolic acid) as inhibitors of hydrogen absorption by steel, and computed quantum chemical characteristics (QCD)

\begin{tabular}{|c|c|c|c|c|c|c|}
\hline \multirow{2}{*}{$\begin{array}{c}\text { Concentration } \\
\text { of Oin, } \\
\text { mMol/L }\end{array}$} & \multicolumn{6}{|l|}{ Pair correlation coefficients between inhibiting efficiencies and QCD } \\
\cline { 2 - 7 } & HOMO & LUMO & $\begin{array}{c}\text { Dipole } \\
\text { moment }\end{array}$ & $\begin{array}{c}\text { Net } \\
\text { Mulliken } \\
\text { charge Q } \\
\text { (Nitrogen1) }\end{array}$ & $\begin{array}{c}\text { Net } \\
\text { Mulliken } \\
\text { charge Q } \\
\text { (Nitrogen2) }\end{array}$ & $\begin{array}{c}\text { Net } \\
\text { Mulliken } \\
\text { charge Q } \\
\text { (Oxygen) }\end{array}$ \\
\hline 0.25 & -66 & 1 & -54 & 63 & -65 & 39 \\
\hline 0.5 & -66 & 1 & -54 & 63 & -65 & 39 \\
\hline 1 & -66 & 1 & -54 & 63 & -65 & 39 \\
\hline
\end{tabular}

Table 5. Correlation coefficients between efficiencies of the studied Oin that are not the derivatives of glycolic acid, as inhibitors of hydrogen absorption by steel, and computed QCD

\begin{tabular}{|c|c|c|c|c|c|c|}
\hline \multirow{2}{*}{$\begin{array}{c}\text { Concentration } \\
\text { of Oin, } \\
\text { mMol/L }\end{array}$} & \multicolumn{5}{|c|}{ Correlation coefficients between inhibiting efficiencies and QCD (\%) } \\
\cline { 2 - 7 } & HOMO & LUMO & $\begin{array}{c}\text { Dip. } \\
\text { moment }\end{array}$ & Q (N1) & Q (N2) & Q (O) \\
\hline 0.25 & 50.9 & 4.8 & -40 & $\mathbf{9 8}$ & -40 & 12 \\
\hline 0.5 & 50.9 & 4.8 & -40 & $\mathbf{9 8}$ & -36 & 12 \\
\hline 1 & 50.8 & 4.8 & -40 & $\mathbf{9 8}$ & -36 & 12 \\
\hline
\end{tabular}

Table 6. Correlation coefficients between efficiencies of the studied $O$ in (derivatives of glycolic acid) as inhibitors of corrosion of steel, and computed quantum chemical characteristics (QCD)

\begin{tabular}{|c|c|c|c|c|c|c|}
\hline \multirow{2}{*}{$\begin{array}{c}\text { Concentration } \\
\text { of Oin, } \\
\text { mMol/L }\end{array}$} & \multicolumn{6}{|c|}{ Correlation coefficients between inhibiting efficiencies and QCD (\%) } \\
\cline { 2 - 7 } & HOMO & LUMO & $\begin{array}{c}\text { Dipole } \\
\text { moment }\end{array}$ & Q (N1) & Q (N2) & Q (O) \\
\hline 0.25 & -66 & 1 & -54 & 63 & -65 & 39 \\
\hline 0.5 & -66 & 1 & -54 & 63 & -65 & 39 \\
\hline 1 & -66 & 1 & -54 & 63 & -65 & 39 \\
\hline
\end{tabular}


Table 7. Correlation coefficients between efficiencies of the studied Oin (that are not the derivatives of glycolic acid) as inhibitors of corrosion of steel, and computed quantum chemical characteristics (QCD)

\begin{tabular}{|c|c|l|l|c|c|c|}
\hline \multirow{2}{*}{$\begin{array}{c}\text { Concentratio } \\
\text { n of Oin, } \\
\text { mMol/L }\end{array}$} & \multicolumn{5}{|c|}{ Correlation coefficients between inhibiting efficiencies and QCD (\%) } \\
\cline { 2 - 7 } & HOMO & LUMO & Dip. moment & Q (N1) & Q (N2) & Q (Oxygen) \\
\hline 0.25 & 51 & 5 & -41 & $\mathbf{9 8 . 5}$ & -36 & 13 \\
\hline 0.5 & 51 & 5 & -41 & $\mathbf{9 8 . 5}$ & -29 & 13 \\
\hline 1 & 51 & 5 & -41 & $\mathbf{9 8 . 5}$ & -28 & 13 \\
\hline
\end{tabular}

Table 8. Correlation coefficients between efficiencies of the studied Oin (derivatives of glycolic acid) as the biocides (against mushroom growth on metal surface), and the computed QCD

\begin{tabular}{|c|c|c|c|c|c|c|}
\hline \multirow{2}{*}{$\begin{array}{c}\text { Concentration } \\
\text { of Oin, } \\
\text { mMol/L }\end{array}$} & \multicolumn{5}{|c|}{ Correlation coefficients between efficiencies of Oin as biocides and QCD (\%) } \\
\cline { 2 - 7 } & HOMO & LUMO & Dip. moment & Q (N1) & Q (N2) & Q (O) \\
\hline 0.25 & -66 & 1 & -54 & 63 & 65 & 39 \\
\hline 0.5 & -66 & 1 & -54 & 63 & 65 & 39 \\
\hline 1 & -66 & 1 & -54 & 63 & 65 & 39 \\
\hline
\end{tabular}

Table 9. Correlation coefficients between efficiencies of the studied Oin (that are not the derivatives of glycolic acid) as the biocides, and computed QCD

\begin{tabular}{|c|c|c|c|c|c|c|}
\hline \multirow{2}{*}{$\begin{array}{c}\text { Concentration } \\
\text { of Oin, } \\
\text { mMol/L }\end{array}$} & \multicolumn{5}{|c|}{ Correlation coefficients between efficiencies of Oin as biocides } \\
and QCD (\%) \\
\cline { 2 - 7 } & HOMO & LUMO & Dip. moment & Q (N1) & Q (N2) & Q (O) \\
\hline 0.25 & 51 & 5 & -40 & $\mathbf{9 8}$ & -36 & 12 \\
\hline 0.5 & 50 & 5 & -40 & $\mathbf{9 8}$ & -28 & 12 \\
\hline 1 & 50 & 5 & -40 & $\mathbf{9 8}$ & -23 & 12 \\
\hline
\end{tabular}

The last two tables show that acceptor properties of the studied Oin (represented by LUMO energies) are not responsible for their biocide action, while net atomic charge on the nitrogen atom (N1) forming one of the two N-H groups in the studied molecules of Oin provides strong correlation with biocide action of only those hydrazides and hydrazones that are not the derivatives of glycolic acid.

The obtained results confirming the special role of dipole moment of Oin molecules agree with previously published data [12-14]. Generally the development of the proposed approach promising in the framework of the prospects of building possibly universal model capable of describing inhibitive action against corrosion and hydrogen absorption by metals in different media and under various conditions. 


\section{UNDERSTANDING MECHANISMS OF INHIBITING ACTION OF N-CONTAINING ORGANIC COMPOUNDS ON CORROSION AND HYDROGEN ABSORPTION OF STEEL USING QUANTUM CHEMICAL COMPUTATIONS}

A correlation analysis of the results of Hartree-Fock $a b$ initio quantum chemical computations and experimentally measured efficiencies of substituted sulphanilamides as inhibitors of corrosion and hydrogen absorption, was used to find ways of understanding the most likely explanations for the mechanisms of their action at the interface between steel and corrosion medium.

The mass-loss corrosion rate (CR) of mild steel was measured after 30 days exposure in aqueous salt media with substituted sulphanilamides (SS) at $1.0 \ldots 10 \mathrm{mMol} / \mathrm{L}$, and 1 of the 4 deuteromicetes (D): Aspergillus niger (D1), Penicillum chrysogenum (D2), P. charlessii (D3), and PhialofOin fastigiata (D4). Hydrogen absorption (HA) by corroded steel measured with the use of anodic dissolution technique corresponds to the corrosion rates. Both CR and HA are accelerated by the deuteromicetes, and their stimulating action is decreasing in the above listed order (1 to 4). The experimentally measured inhibitive efficiencies (IE) on CR (listed in Table 10 below) are analysed together with the obtained quantum chemical results using pair correlation technique.

Table 10. Corrosion Inhibiting Efficiencies of the Series of N-containing Organic Compounds at Presence of Deutemomicetes

\begin{tabular}{|c|c|c|r|r|r|c|}
\hline Deuteromicete: & \multicolumn{3}{c|}{ Aspergillus niger (D1) } & \multicolumn{3}{c|}{ Penicillum chrysogenum (D2) } \\
\hline SS, mMol/L & 1 & 2 & 5 & 1 & 2 & 5 \\
\hline IE (SS1), \% & 68 & 77 & 94 & 64 & 81 & 95 \\
\hline IE (SS2), \% & 44 & 60 & 78 & 56 & 75 & 86 \\
\hline IE (SS3), \% & 84 & 89 & 94 & 55 & 75 & 84 \\
\hline IE (SS4), \% & 82 & 86 & 94 & 52 & 40 & 81 \\
\hline
\end{tabular}

As seen from the Table 11 below, there is steady correlation between the efficiencies of SS against corrosion and certain quantum chemical characteristics (HOMO and LUMO energies of the free SS molecules, Mulliken net charges on the atoms that comprise the active centres of SS molecules).

Table 11. Correlation Coefficients between the Computed Parameters of SS Isolated Molecules and AntiCorrosion Inhibitive Efficiencies

\begin{tabular}{|c|c|c|c|c|c|c|}
\hline $\begin{array}{c}\text { Pair } \\
\text { correlations } \\
\begin{array}{c}\%) \text { between } \\
\text { IE and: }\end{array}\end{array}$ & $\begin{array}{c}(D 1), \\
1 \mathrm{mMol} / \mathrm{L}\end{array}$ & $\begin{array}{c}\text { (D1), across } \\
\text { all SS conc. }\end{array}$ & $\begin{array}{c}\text { (D2), across } \\
\text { all SS conc. }\end{array}$ & $\begin{array}{c}\text { (D3), across } \\
\text { all SS conc. }\end{array}$ & $\begin{array}{c}(\mathrm{D} 4), \\
\mathrm{mMol} / \mathrm{L}\end{array}$ & $\begin{array}{c}\text { (D4), across } \\
\text { all SS conc. }\end{array}$ \\
\hline HOMO & 44 & 33 & -48 & -5 & -84 & -47 \\
\hline LUMO & 47 & 33 & -36 & -64 & -64 & -40 \\
\hline Q (S) & -76 & -55 & 39 & 68 & 69 & 31 \\
\hline Q (O) & -49 & -36 & 39 & 72 & 76 & 44 \\
\hline Q (N) & -70 & -51 & 40 & 69 & 71 & 34 \\
\hline $\begin{array}{c}\text { Dipole } \\
\text { moment }\end{array}$ & 70 & 53 & -44 & -81 & -89 & -42 \\
\hline
\end{tabular}


The present work continues a series of publications $[15,16]$ introducing our approach in understanding mechanisms of inhibiting action of N-containing organic compounds on both corrosion and hydrogen absorption of steel. The quantum chemical data compared in Table 11 with the experimentally measured efficiencies of corresponding inhibitors listed in Table 10, were obtained using Gaussian software [11].

Results shown in Table 11 suggest that different action mechanisms are involved in inhibitive action for different deuteromicetes: dipole moment calculated for the SS molecules, shows in general stronger correlation with EI than other tested quantum chemical characteristics (energies of highest occupied molecular orbital HOMO that characterizes electron donating properties of the molecules $[15,16]$, energy of lowest unoccupied molecular orbital LUMO which characterizes electron accepting molecular properties, and net Mulliken atomic charges on heteroatoms of the molecular system studied - S, O, N). Even if we take, again, just dipole moment, then it is possible to see that the sign of the pair correlation coefficient is different for D1 compared to the rest of deuteromicetes (D2, D3, D4). Quantum chemical data were obtained not only for the isolated molecules, but also for the individual SS molecules each adsorbed on model metal cluster containing $6 \mathrm{Fe}$ atoms thus representing metal (steel) surface.

\section{PREDICTION OF EFFICIENCY OF ORGANIC INHIBITORS USING QUANTUM CHEMICAL MODELLING OF INHIBITION OF CORROSION AND HYDROGEN ABSORPTION OF METALS}

To predict inhibitive efficiency of an organic compound, thus avoiding redundant costly organic synthesis making it a purposeful one, one needs correlation analysis of protective efficiencies together with quantum chemical results. Ab initio computations were performed with the use of Gaussian software. Experimental efficiencies (measured for 8 diantipirylmethane derivatives, OIn) are reported in Table 12 below.

Table 12. Experimentally measured efficiencies of studied Oln

\begin{tabular}{|c|c|c|c|c|c|c|}
\hline Efficiencies: & \multicolumn{3}{|c|}{ against corrosion, $\%$} & \multicolumn{3}{c|}{ against hydrogen absorption, $\%$} \\
\hline mMol/L & 1 & 5 & 10 & 1 & 5 & 10 \\
\hline Notification: & Cor1 & Cor5 & Cor10 & Hab1 & Hab5 & Hab10 \\
\hline OI1 & 45 & 66 & 76 & 26 & 43 & 50 \\
\hline OI2 & 53 & 70 & 78 & 54 & 56 & 59 \\
\hline OI3 & 67 & 75 & 79 & 28 & 54 & 57 \\
\hline OI4 & 61 & 69 & 78 & 23 & 51 & 53 \\
\hline OI5 & 40 & 68 & 70 & 13 & 47 & 48 \\
\hline
\end{tabular}


Table 13. Internal Pair Correlations (\%) between various Quantum Chemical Results

\begin{tabular}{|c|c|c|c|c|c|c|c|}
\hline HOMO & & & & & & & \\
\hline LUMO & 94 & & & & & & \\
\hline$\Delta \mathrm{E}$ & -98 & -99 & & & & & \\
\hline Charge (N) & 98 & 89 & -94 & & & & \\
\hline Charge (O) & -55 & -53 & 54 & -68 & & & \\
\hline$\Sigma \mathrm{Q}(\mathrm{C})_{i}$ & -96 & -85 & 91 & -96 & 56 & & \\
\hline Charge $\left(C^{*}\right)$ & 17 & 94 & -12 & 17 & 12 & 4 & \\
\hline$\mu, D$ & -97 & -54 & 91 & -96 & 47 & 90 & -38 \\
\hline & HOMO & LUMO & $\Delta \mathrm{E}$ & $\mathrm{Q}(\mathrm{N})$ & $\mathrm{Q}(\mathrm{O})$ & $\Sigma \mathrm{Q}(\mathrm{C})_{i}$ & $\mathrm{Q}\left(\mathrm{C}^{*}\right)$ \\
\hline
\end{tabular}

The resulting pair correlation coefficients are listed in the table below $\left(\Sigma \mathrm{Q}(\mathrm{C})_{i}\right.$ denotes sum of Mulliken charges on benzene ring. Adsorption model consisted of 1 OIn molecule on 12-atom Fe cluster). Non-significant correlations (shown in Table 13) are truncated. Results give evidence of the mixed type of inhibitive action.

Table 14. Correlation coefficients between quantum chemical data obtained for the isolated molecules of OIn using software [11], and experimentally measured efficiencies of corresponding OIn against corrosion

\begin{tabular}{|c|c|c|c|c|c|c|}
\hline Properties & Cor1 & Cor5 & Cor10 & Hab1 & Hab5 & Hab10 \\
\hline HOMO & 76 & 91 & - & - & - & - \\
\hline LUMO & 82 & 88 & 71 & - & - & 64 \\
\hline$\Delta \mathrm{E}$ & 81 & 90 & 62 & - & - & 57 \\
\hline $\mathrm{Q}(\mathrm{N})$ & 63 & 89 & - & - & - & - \\
\hline $\mathrm{Q}(\mathrm{O})$ & - & - & - & - & - & - \\
\hline$\Sigma \mathrm{Q}(\mathrm{C})_{i}$ & -60 & -75 & - & - & - & - \\
\hline $\mathrm{Q}\left(\mathrm{C}^{*}\right)$ & - & - & - & - & 79 & - \\
\hline$\mu, \mathrm{D}$ & -75 & -94 & - & - & - & - \\
\hline
\end{tabular}

Anaerobic corrosion is one of the most dangerous types of microbiological corrosion, the sulphate reducing bacteria (SRB) being the main exciters of such corrosion. Certain organic substances perform double action, both as corrosion inhibitors and bactericides (possibly even being first of all bactericides and thus indirectly inhibiting corrosion).

In the present work, results of our study of diantipirylalkanes as inhibitors of corrosion and hydrogen absorption by steel $\mathrm{CrNi} 1810$ are reported together with the simultaneous evaluation of their bactericide action against SRB.

The experimental measurements were proceeded using Postgate $\mathrm{B}$ media at $37^{0} \mathrm{C}$, corrosion rate measured gravimetrically. The following parameters were controlled during exposition of the specimen: $\mathrm{pH}$ and $\mathrm{E}_{\mathrm{h}}$ of the media, concentration of biogenic $\mathrm{H}_{2} \mathrm{~S}$ in it, SRB bacterial titer and electrode potential of the specimen. Spectrophotometer SF-46 was used to measure the distribution coefficient (WHDC) for the studied OIn molecules between the two noninteracting liquids (water and n-hexane that models bacterial membrane). After 48 hours of exposition, the specimens made of stainless steel together with OIn were put into the media containing the developing SRB. 


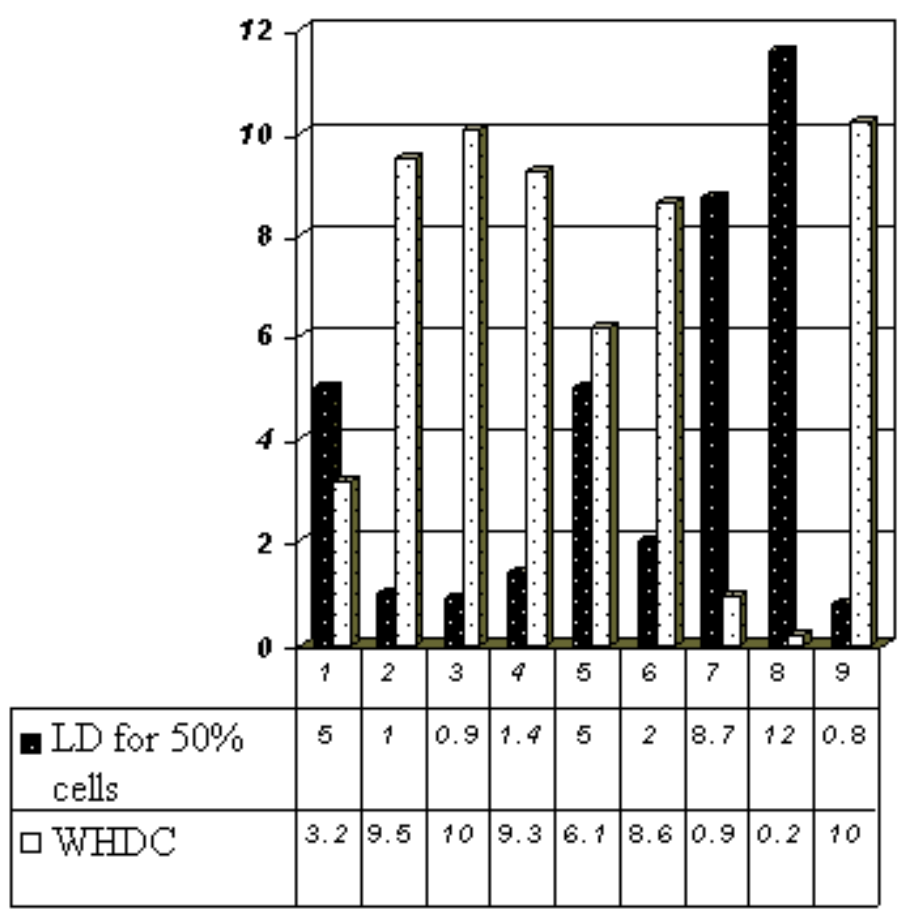

Fig. 1. Relation between $\mathrm{LD}_{50}$ and WHDC

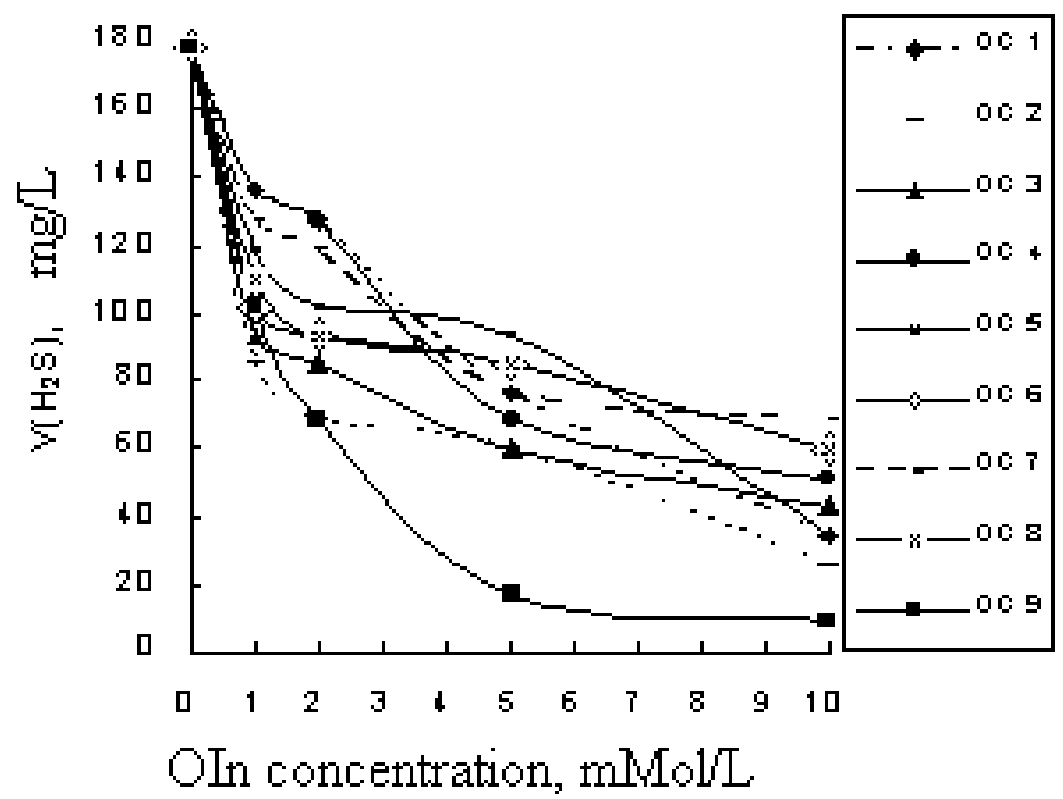

Fig. 2. Dependence of $\mathrm{H}_{2} \mathrm{~S}$ content on Oln concentration in the media 
Experimentally measured values are listed in Table 12.

Table 13 is based on internal correlations [17] between the quantum chemical results of the theoretical study, and suggests that either $\triangle \mathrm{E}=\mathrm{LUMO}-\mathrm{HOMO}$ or, for example, LUMO results be excluded due to the fact of their strong inter-correlation $(\boldsymbol{r}=-99 \%)$. Computed dipole moment $\mu$ of isolated OIn molecules strongly correlates with HOMO energy $(\boldsymbol{r}=-97 \%)$ and charge on $\mathrm{N}$ atom of OIn $(\boldsymbol{r}=-96 \%)$.

Addition of the studied OIn into the corrosive media results in suppression of SRB activity. The reverse dependence between 50\% Lethal Dose $\left(\mathrm{LD}_{50}\right)$ and the above mentioned WHDC has been estimated (see Fig.1). Inhibiting efficiency of the studied OIn against microbiological corrosion reaches $70 \div 80 \%$, and against hydrogenation of steel $-50 \div 70 \%$ at OIn concentration

$10 \mathrm{mMol} \mathrm{L}^{-1}$. All studied OIn efficiently suppress bacterial sulphate reduction, minimal $\mathrm{H}_{2} \mathrm{~S}$ content in the closed anaerobic system reached at OIn concentration $10 \mathrm{mMol} \mathrm{L}^{-1}$ (Fig. 2). Some of the important experimentally obtained dependencies giving additional understanding of the proposed models of inhibitive action [2] are shown as Fig. $3 \div$ Fig. 8 .

Our results give evidence of the mixed type of inhibitive action (in the case of corrosion, mechanism of electron donation by OIn represented by HOMO [17] line in Table 14 prevails on electron accepting action of OIn represented by LUMO [17] line of the same Table).

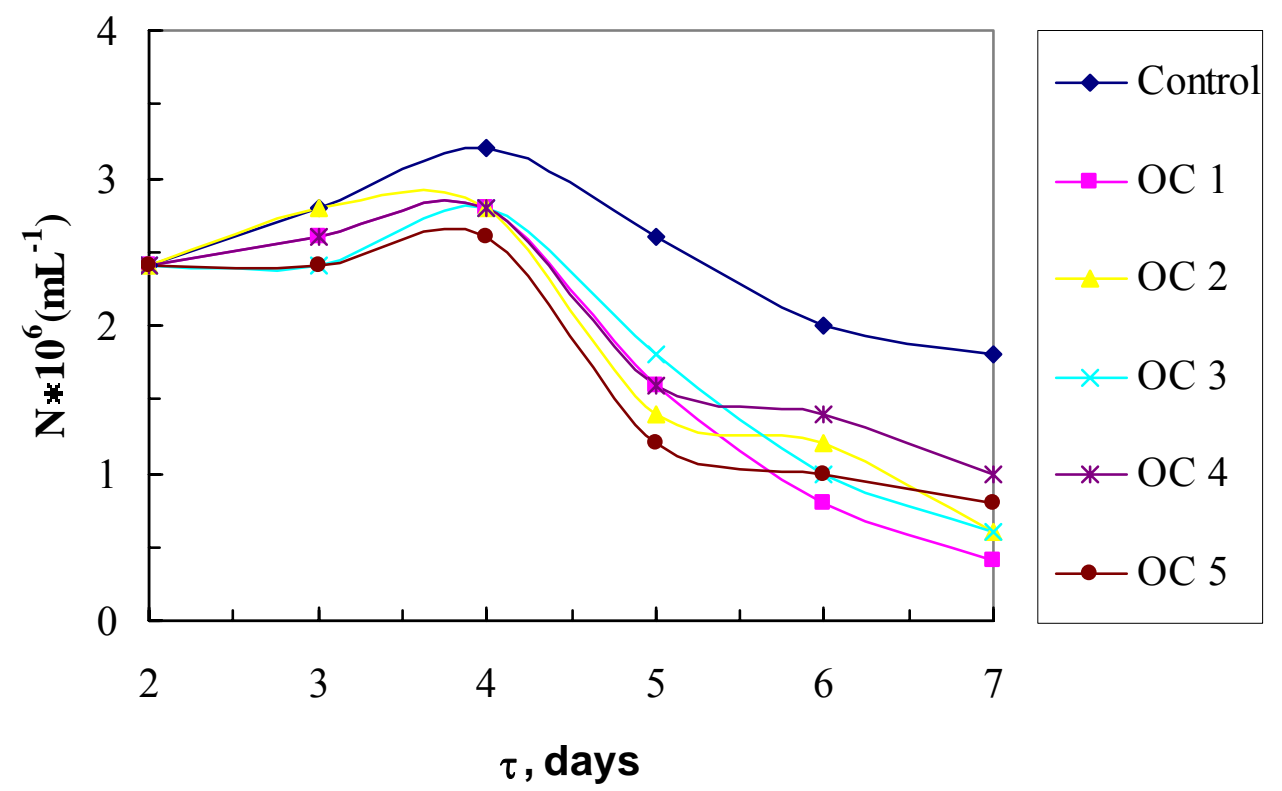

Fig. 3. Number of SRB cells as a function of exposure time in aqueous salt corrosion medium in the presence of organic compounds at concentration $5 \mathrm{mM} \cdot \mathrm{L}^{-1}$ 


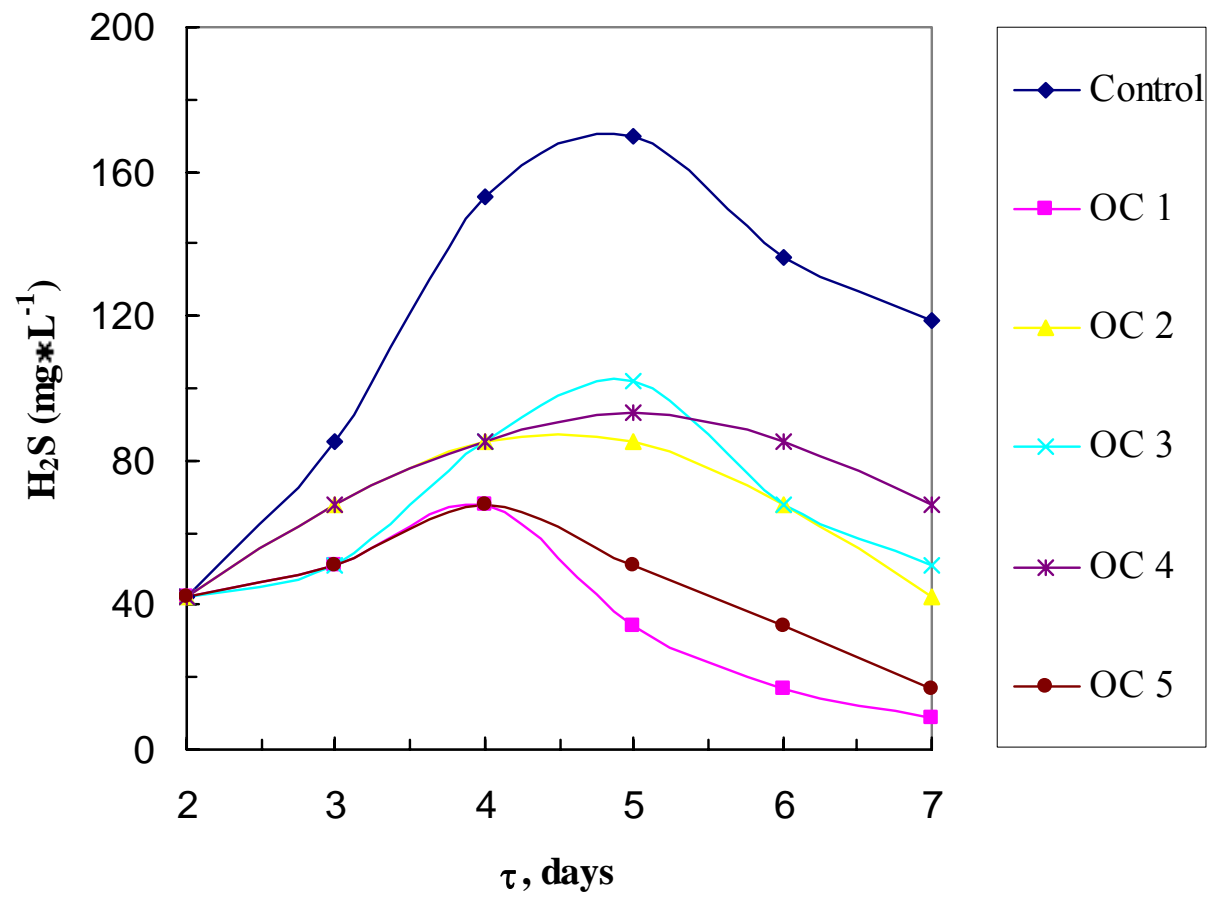

Fig. 4. Changes in the values of hydrogen sulfide concentration with exposure time for the system "Stainless steel-Postgate B medium with SRB" in the presence of organic compounds at concentration $5 \mathrm{mM} \cdot \mathrm{L}^{-1}$

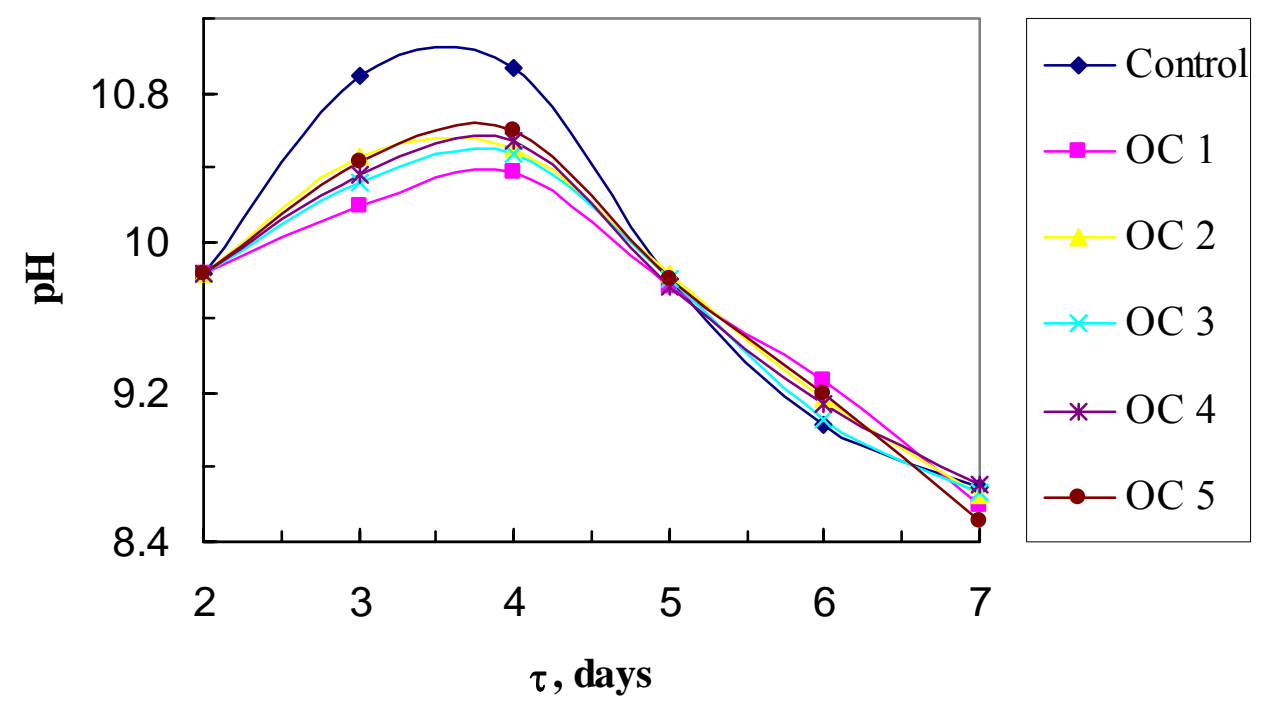

Fig. 5. Changes in the $\mathrm{pH}$ values with exposure time for the system "Stainless steel-Postgate $\mathrm{B}$ medium with SRB" in the presence of organic compounds at concentration $5 \mathrm{mM} \cdot \mathrm{L}^{-1}$ 


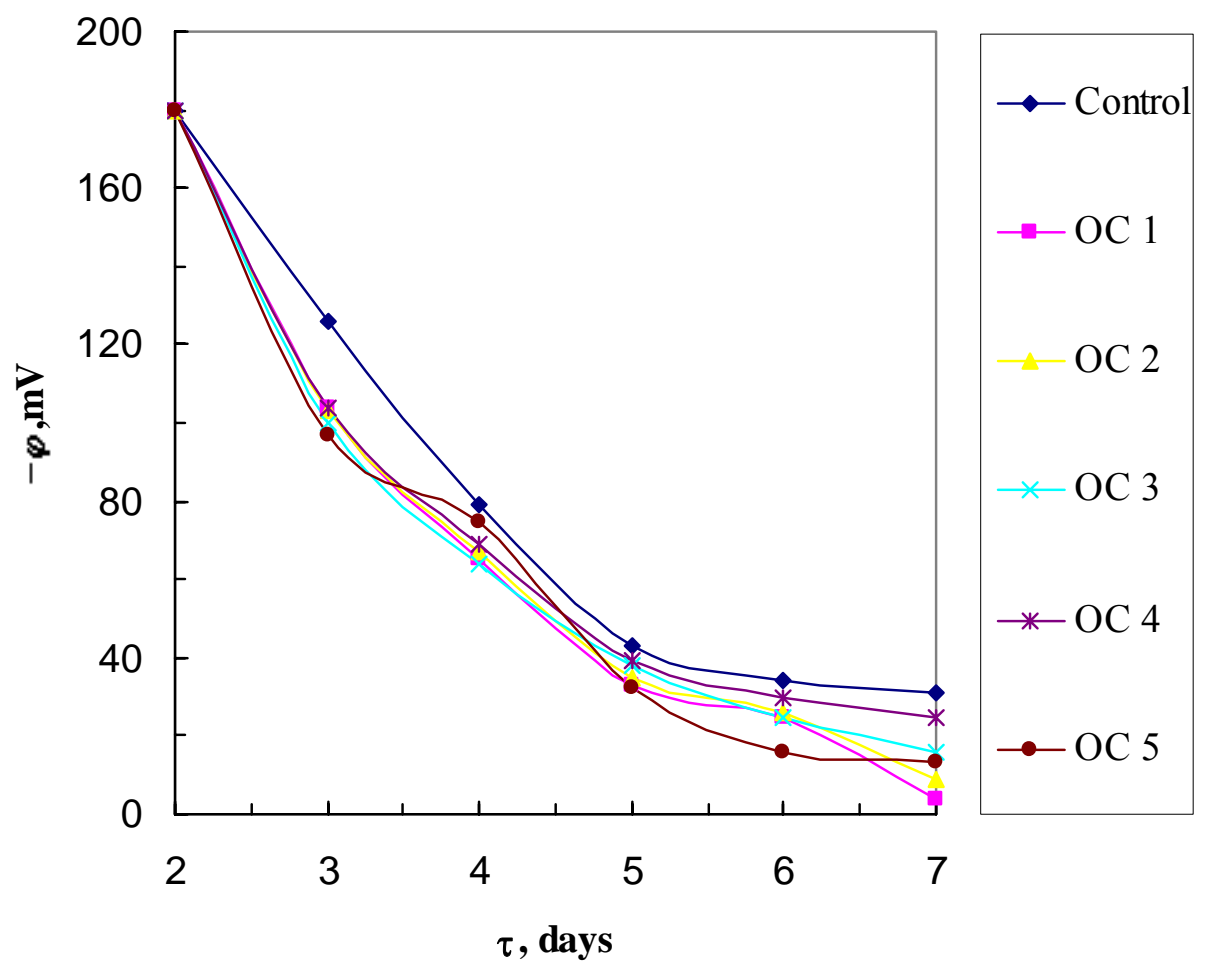

Fig. 6. Changes in the values of electrode potential of steel specimens with exposure time for the system "Stainless steel-Postgate B medium with SRB" in the presence of organic compounds at concentration $5 \mathrm{mM} \cdot \mathrm{L}^{-1}$

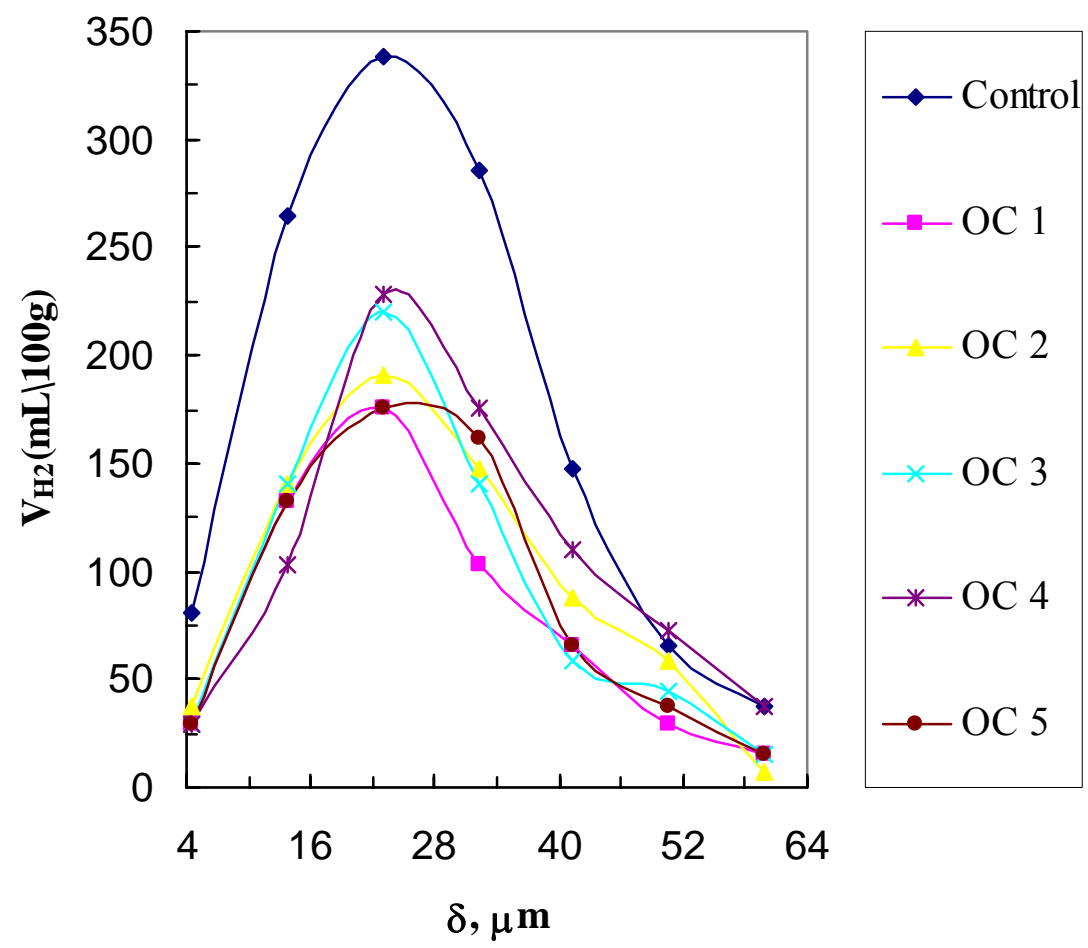

Fig. 7. Hydrogen distribution across the depth of stainless steel specimens (electrolyte contains organic compounds at concentration $5 \mathrm{mM} \cdot \mathrm{L}^{-1}$ ) 


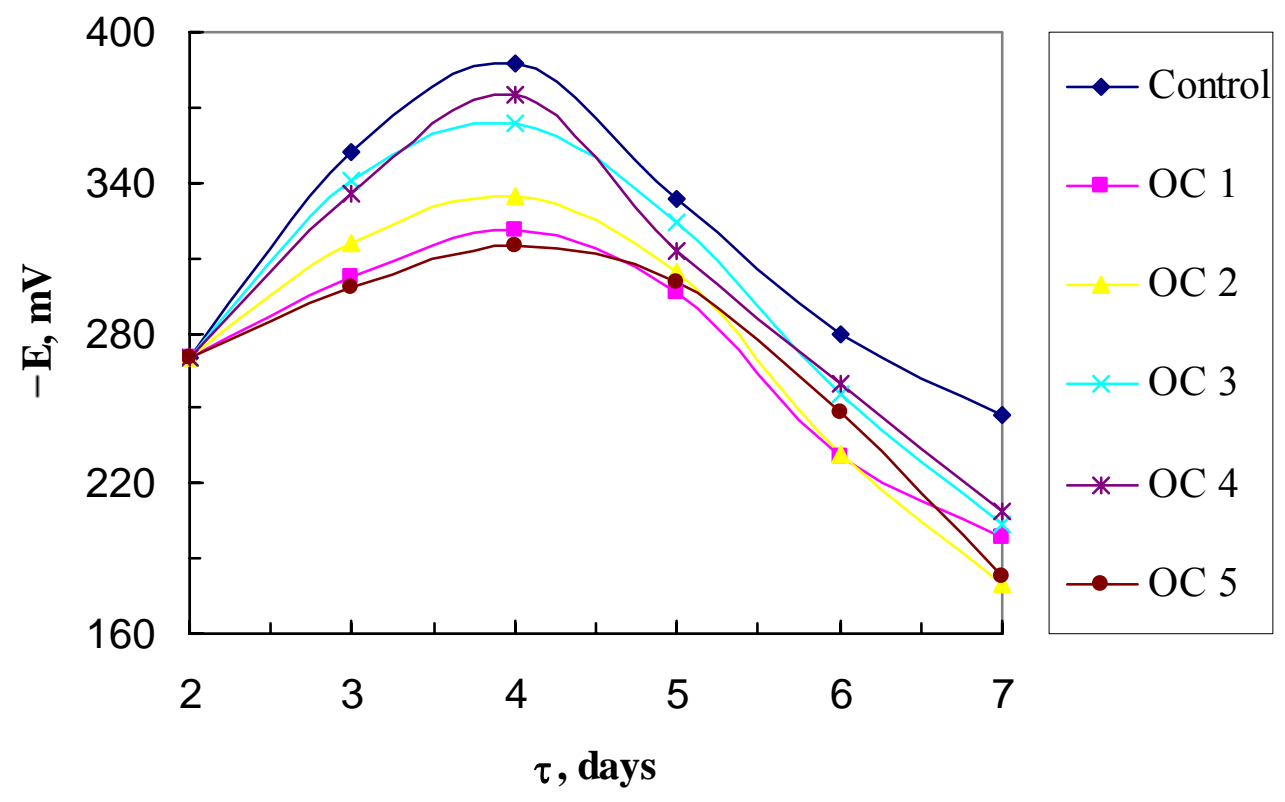

Fig. 8. Changes in the values of redox potential exposure time for the system "Stainless steel-Postgate B medium with SRB" in the presence of organic compounds at the concentration of $5 \mathrm{mM} \cdot \mathrm{L}^{-1}$

Table 14 shows also that in case of hydrogen absorption by steel, only electron accepting properties (characterized by LUMO energy) of OIn studied as well as their molecule charge distribution in the area of certain carbon atom marked in Tables 13, 14 as $\mathrm{C}^{*}: r(\mathrm{Hab} 5)=79 \%$, are important from the point of OIn inhibiting efficiency.

On the opposite, in case of corrosion, this characteristics shown in Table 5.4.3 as $\mathrm{Q}\left(\mathrm{C}^{*}\right)$, is obviously not important in understanding the inhibitive action, while the other three - namely, net Mulliken charge on nitrogen as certain active point of the OIn Q(N), sum of Mulliken charges on carbon forming benzene ring fragment as the molecule active centre $\Sigma \mathrm{Q}(\mathrm{C})_{i}$, and dipole moment $\mu$ of isolated molecule - seem essential $(\boldsymbol{r}=89 \%, \boldsymbol{r}=-75 \%$, and $\boldsymbol{r}=-94 \%$ respectively at OIn concentration $\mathrm{c}=5 \mathrm{mMol} / \mathrm{L}$ ).

\section{ACKNOWLEDGEMENT}

The author thanks PhD. Dmitry Maliarewskiy for his kind aid in obtaining the results of calculations brought in Tables $4-9$.

\section{REFERENCES}

1. Beloglazov S.M., Beloglazov G.S., Uss S.N. Corrosion and hydrogen absorption inhibitors with biocide action against sulphate reducing bacteria, in: Progress in the Understanding and Prevention of Corrosion // Progress in the Understanding and Prevention of Corrosion: Proc. / 10th European Congress. Barcelona. 1993. J.M. Costa, A. D. Mercer (Eds.). Vol. 2, pp. 11851189. 
2. Beloglazov S.M., Beloglazov G.S. Correlation of Quantum Chemical Study of Organic Compounds with their Corrosion and Hydrogen Absorption Efficiency // Eurocorrosion-94: Conference Papers. Bournemouth. 1994. Vol. 3, pp. 94-100.

3. Beloglazov S.M., Beloglazov G.S. Inhibitors of Steel Corrosion and Hydrogen Adsorption in Two-Phase System of Gas Pipelines // Abstracts: 3rd European Federation of Corrosion Workshop on Microbial Corrosion / Estoril Portugal, March 1994, pp. 64.

4. Beloglazov S.M., Beloglazov G.S., Myamina A.A. Corrosion and Hydrogen Absorption Inhibitors with Biocyde Action Against Sulphate Reducing Bacteria // Proc.: 46th Ann. Meeting Int. Soc. of Electrochem. / Xiamen, China. 1995, pp. 7-11.

5. Beloglazov S.M., Gorilenko N.N., Beloglazov G.S. Microbiological corrosion of mild steel at the presence of sulphate reducing bacteria: The influence of inhibitors and stimulators of hydrogen absorption // Corrosion in natural and industrial environments: Problems and industrial solutions. Grado, 1995, pp. 211-218.

6. Beloglazov S.M., Beloglazov G.S., Poljudova V.P. Inhibitors of Steel Corrosion and Hydrogen Absorption in Two-Phase System of Gas Pipelines // Ann. Univ. Ferrara N.S.Sez. V Suppl. 1995. N 10, pp.1327-1331.

7. Beloglazov G.S., Beloglazov S.M. Quantum chemical study of nitrogen and sulphur containing substances as inhibitors of the corrosion and hydrogenation of steel // Development in Marine Corrosion, S.A. Campbell, N. Campbell and F.C. Walsh (Eds.), The Royal Soc. Chem., Cambridge. 1998, pp. $143-154$.

8. Beloglazov G.S., Beloglazov S.M., Gryaznova M.V. // EMCR'2006: Proc. France, 2006, p. 37.

9. Beloglazov G.S., Gryaznova M.V., Beloglazov S.M. Prediction of Efficiency of Organic Inhibitors using Quantum Chemical Modeling of Inhibition of Corrosion and Hydrogen Absorption of Metals // EUROCORR 2004. Nice, France. 2004 / Proc. CD ROM. 6 p.

10. Beloglazov G.S., Myamina A.A., Beloglazov S.M. Understanding Mechanisms of Inhibiting Action of N-containing Organic Compounds on Corrosion and Hydrogen Absorption of Steel using Quantum Chemical Computations // EUROCORR 2004. Nice, France. 2004 / Abstracts, p. 39.

11. Gaussian 94 // Revision E3 / M.J. Frisch, G.W. Trucks e.a., Gaussian, Inc., Pittsburgh PA. 1995.

12. Beloglazov G.S., Gryaznova M.V., Beloglazov S.M. Quantum chemical study of pyrazoline derivatives as inhibitors of hydrogenation and SRB-induced corrosion of steel // 55th ISE Annual Meeting of ISE. Thessalonica, Greece. 2004 / Abstracts, Vol. 2. p. 942.

13. Beloglazov S.M., Beloglazov G.S., Laykova M.N. Experimental and quantum chemical study of benzenesulfonamide derivatives as inhibitors of hydrogen absorption and microbiological corrosion of Ni-coated steel in aqueous media // Proc. 10 Europ. Symp. on Corros. and Scale Inhib. (SEIC) / Ferrara, 2005. Sez. 5, Suppl. 12, pp. 505-516.

14. Beloglazov G.S., Beloglazov S.M. Quantum chemical study of adsorption of organic inhibitors on $\mathrm{Al}$ and $\mathrm{Cd}$ surfaces // Achievements and prospects in development of new medicinal drugs: Material Russ. Sci.-Pract. Conf... 70 Anniv. PSPhA. Perm. 2007, pp. 163-167.

15. Beloglazov G.S., Beloglazov S.M., Gladysh O.D. Quantum Chemical Study of Corrosion Inhibitive Action of Organic Substances // Progress in the Understanding and Prevention of Corrosion: Proc. / 10th European Congress. Barcelona, 1993, pp. 900-905.

16. Beloglazov S.M., Myamina A.A., Beloglazov G.S. Corrosion and Hydrogen Absorption Inhibitors with Biocyde Action Against Sulphate Reducing Bacteria // IX Int. Congress on Marine Corrosion and Fouling / Abstracts. Portsmouth. 1995.

17. Landau M.A. Molecular Mechanisms of Action of Physiologically Active Compounds, 3-rd edition. M., 1979. - p. 323 